\title{
Transient stability of a hydro-turbine governing system with different tailrace tunnels
}

HAO ZHANG, PhD Student, Institute of Water Resources and Hydropower Research, Northwest A\&F University, Shaanxi Yangling, P. R. China

Email: hao_zhang@nwsuaf.edu.cn

WENTAI PANG, Researcher, Inner Mongolia Water Resources and Hydropower Survey and Design Institute, Hohhot, P. R. China

Email:32729409@qq.com

DIYI CHEN, Professor, Key Laboratory of Agricultural Soil and Water Engineering in Arid and Semiarid Areas, Ministry of Education, Northwest A\&F University, Shaanxi Yangling, P. R. China; Institute of Water Resources and Hydropower Research, Northwest A\&F University, Shaanxi Yangling, P. R. China; Australasian Joint Research Centre for Building Information Modelling, School of Built Environment, Curtin University, WA, Australia

Email:diyichen@nwsuaf.edu.cn (author for correspondence)

YU TIAN, Researcher, State Key Laboratory of Simulation and Regulation of Water

Cycle in River Basin, China Institute of Water Resources and Hydropower Research, Beijing, China; College of Water Conservancy and Hydropower Engineering, Hohai University, Nanjing, China

Email: sweetrain511@163.com (author for correspondence)

EDOARDO PATELLI, Associate Professor, Institute for Risk and Uncertainty, School of Engineering, University of Liverpool, Liverpool, United Kingdom

Email: Edoardo.Patelli@liverpool.ac.uk

CHAOSHUN LI, Professor, School of Hydropower and Information Engineering, Huazhong University of Science and Technology, Wuhan, China

Email:csli@hust.edu.cn

JIANZHONG ZHOU, Professor, School of Hydropower and Information Engineering, Huazhong University of Science and Technology, Wuhan, China

Email:jz.zhou@mail.hust.edu.cn 


\section{Abstract}

This paper focuses on the transient stability of a hydro-turbine governing system with three kinds of tailrace tunnels. As the transfer coefficients change with operation conditions, the dynamic transfer coefficients which can describe the transient characteristics of the hydro-turbine governing system are introduced. Then, the transient stability of the hydro-turbine governing system is analyzed. The global bifurcation diagrams for the three kinds of tailrace tunnels are respectively presented to investigate the effects of the tailrace tunnels on the stability of the hydro-turbine governing system. Furthermore, theoretical analysis which proves the validity of simulation results is provided to explain the effects of the flow inertia and water level fluctuation. In addition, the influence of the tailrace tunnel gradient on the transient stability is also studied. More importantly, these methods and research results provide theoretical guidance for the arrangement of the tailrace tunnel and the operation of the hydropower station.

Keywords: hydraulic transient; hydro-turbine; transient process; dynamics; stability

\section{Introduction}

A tailrace tunnel is an essential part of hydropower stations and it has three kinds, namely free flow tunnel, pressurized flow tunnel and tailrace tunnel with sloping ceiling (Cheng, Li \& Yang, 2007; Romero-Gomez \& Richmond, 2017; Skripkin, Tsoy, Shtork \& Hanjalic, 2016). The main characteristic of free flow tunnel is that the flow in it is in the state of open flow and the tunnel is straight. The free flow tunnel is suitable for hydropower stations with large variation of water level. For pressurized flow tunnel, the flow through the entire tunnel is in the state of pressurized flow. The flow velocity is low and the flow state is steady. The tailrace tunnel with sloping ceiling (i.e. the height of the tunnel changes with its length) is a new form of tailrace system for hydropower stations. It is able to adjust the length of open flow section and pressurized flow section according to the level of tail water, which can improve the 
transient performance of the hydropower station during transient processes. Therefore, it can replace the tailrace surge tank under specific conditions (Wei, Su, Li, Li \& Guo, 2014; Zeng, Guo, Zhang, Xu \& Dong, 2013; Chitrakar, Neopane \& Dahlhaug, 2016).

Thus, it has the ability to reduce the investment costs and also to provide alternative solutions. This solution allows to divide the tailrace tunnel into open flow and pressurized flow having the effect of the tailrace surge tank. It ensures that the tailrace system is able to meet the requirements of the regulators (Chitrakar, Neopane \& Dahlhaug, 2016) and provides steady operation of the unit. In summary, tunnels with sloping ceiling have a bright potential in the design of tailrace system and it deserves great attention.

At present, the study on the tailrace tunnel with sloping ceiling mainly includes two aspects: The first aspect is to analyze the effect of the flow regime of the free surface-pressure flow as prescribed by the regulators (Khan, Shahzad, Hayat \& Miah, 2016; Chen, Ding, Ma, Yuan \& Ba, 2013; Anup, Lee \& Thapa, 2016; Kim, Jo, Park, Shin \& Chung, 2017). The second aspect is to study the influence of the load fluctuation on the stable operation of the unit and the regulation quality of the governing system. While the first aspect has already received a lot of consideration from the community (Li, Bi, Karney, Wang \& Yao, 2017; Ciocan, Susan-Resiga \& Muntean, 2016; Li, Chen, Zhang, Wu \& Wang, 2017; Fecarotta, Carravetta, Ramos \& Martino, 2016), few studies have addressed the stability problem of the hydro-turbine unit (Xu, Wang, Chen \& Zhang, 2016; Shimokawa, Furukawa, Okuma, Mastsushita \& Watanabe, 2012) and more comprehensive and systematic research are required.

This paper addresses the transient dynamic stability of the hydro-turbine governing system with inclined ceiling tailrace. It provides theoretical analysis of the influence of the free surface-pressure flow on the stability of the system. Finally, the effect of the gradients of the inclined ceiling tailrace on the transient quality is analyzed in detail by using numerical simulation.

\section{The hydro-turbine governing system with inclined ceiling}

\section{tailrace}




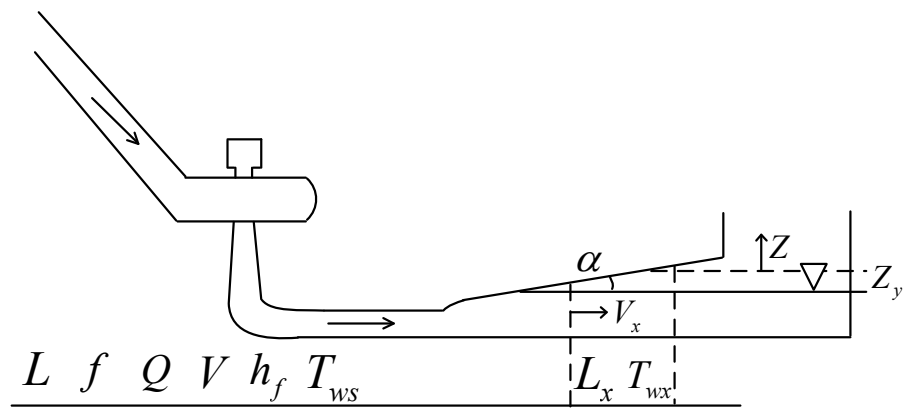

Figure 1 Hydropower station with inclined ceiling tailrace.

The penstock system and power generation system of a hydropower station with inclined ceiling tailrace are shown in Figure 1. The symbol in the figure are defined in the following part of this section. There is reciprocating motion of free surface-pressure flow in the tailrace tunnel with sloping ceiling during the process of load adjustment. This can cause the change of flow inertia and the fluctuation of turbine head. Therefore, the characteristics of the hydropower station with inclined ceiling tailrace are more complex compared to those with pressurized flow tunnel.

For the hydropower station with pressurized flow tunnel, the dynamic equation of the penstock can be written as:

$$
2 h_{f} q+h H_{0}+\frac{L Q_{0}}{g f} \frac{d q}{d t}=0
$$

Then, the Eq. (1) can be written as (Guo, Yang, Wang \& Lai, 2015):

$$
h=-T_{w} \frac{d q}{d t}-\frac{2 h_{f}}{H_{0}} q
$$

where $h=\left(H-H_{0}\right) / H_{0}$ and $q=\left(Q-Q_{0}\right) / Q_{0}$ denote the relative deviations of the turbine head and hydro-turbine unit discharge, respectively. The subscript 0 denotes the initial value. $H_{0}, T_{w}, h_{f}, L$ and $f$ denote the initial turbine head, the time constant of flow inertia, the head loss in penstock, the length of penstock and sectional area of penstock, respectively.

For a hydropower station with inclined ceiling tailrace, the flow inertia in the penstock consists of steady state and transient state. The corresponding time constants are $T_{w s}$ and $T_{w x}$ where $T_{w s}=L V /\left(g H_{0}\right), T_{w x}=L_{x} V_{x} /\left(g H_{0}\right)$ and $T_{w}=T_{w s}+T_{w x} . V$ 
and $g$ denote the velocity of the water and the gravity, respectively. $L_{x}$ is the relative distance of the free surface-pressurized flow. The water level fluctuation in open channel is denoted by $Z$ and the initial stable water level is 0 . The variable quantity of water level is represented by $Z_{y}$ and $z_{y}=Z_{y} / H_{0}$. The dynamic equation of the penstock is as follows:

$$
h=-\left(T_{w s}+T_{w x}\right) \frac{d q}{d t}-\frac{2 h_{f}}{H_{0}} q-z_{y} .
$$

For general tailrace tunnel with $2-4 \%$ sloping ceiling it is reasonable to assume that the wave crest of the free surface-pressure flow always moved along the tunnel (Lai, Chen \& Yang, 2001). Hence, the continuity equation of flow can be obtained as

$$
\left(Q-Q_{0}\right) \Delta t=L_{x} Z_{y} B / \lambda .
$$

where $L_{x}=\frac{\lambda Q_{0}}{c B \tan \alpha} q$ and $T_{w x}=\frac{\lambda Q_{0}}{g H_{0} c B \tan \alpha} q$. As $Z_{y}=L_{x} \tan \alpha, z_{y}=\frac{\lambda Q_{0}}{H_{0} c B} q$. $\lambda$ and $\alpha$ denote the cross-section coefficient of tailrace tunnel and the gradient of the inclined ceiling tailrace, respectively. Eq. (5) is then obtained by using the equations of $T_{w x}$ and $z_{y}$.

$$
h=-\frac{\lambda Q_{0} V_{x}}{g H_{0} c B \tan \alpha} q \frac{d q}{d t}-T_{w s} \frac{d q}{d t}-\left(\frac{2 h_{f}}{H_{0}}+\frac{\lambda Q_{0}}{H_{0} c B}\right) q,
$$

where $B, c$ and $V_{x}$ are the width of inclined ceiling tailrace, wave velocity of free surface flow and flow velocity of the interface of the free surface-pressurized flow, respectively.

The moment equation and flow equation of the hydro-turbine are

$$
m_{t}=e_{h} h+e_{x} x+e_{y} y
$$

and

$$
q=e_{q h} h+e_{q x} x+e_{q y} y .
$$

where $e_{h}, e_{x}$ and $e_{y}$ are partial derivatives of the hydro-turbine torque with 
respect to head, turbine speed and guide vane opening, respectively. $e_{q h}, e_{q x}$ and $e_{q y}$ denote partial derivatives of the flow with respect to head, turbine speed and guide vane opening, respectively.

The dynamic characteristics of generator and load can be expressed as

$$
T_{a} \frac{d x}{d t}=m_{t}-\left(m_{g}+e_{g} x\right)
$$

where $x=\left(n-n_{0}\right) / n_{0}, \quad m_{t}=\left(M_{t}-M_{t 0}\right) / M_{t 0}$ and $m_{g}=\left(M_{g}-M_{g 0}\right) / M_{g 0}$ denote the relative derivations of turbine speed, kinetic moment and resisting moment, respectively. The subscript 0 denotes the initial value. $T_{a}$ and $e_{g}$ are the inertia time constant of the unit and self-regulation coefficient of load.

The dynamic characteristics of hydraulic servo system can be obtained as

$$
\frac{d y}{d t}=-K_{p} \frac{d x}{d t}-K_{i} x
$$

where $y=\left(Y-Y_{0}\right) / Y_{0}, K_{p}$ and $K_{i}$ denote the relative deviation of guide vane opening, proportional adjustment coefficient and integral adjustment coefficient, respectively. The subscript 0 denotes the initial value.

From Eq. (5)-(9), the dynamic model of the hydro-turbine governing system with inclined ceiling tailrace can be written as

$$
\left\{\begin{array}{l}
x^{\prime}=\frac{1}{T_{a}}\left[\frac{e_{h}}{e_{q h}} q+\left(e_{x}-\frac{e_{h}}{e_{q h}} e_{q x}-e_{g}\right) x+\left(e_{y}-\frac{e_{h}}{e_{q h}} e_{q y}\right) y-m_{g}\right] \\
y^{\prime}=-\frac{K_{p}}{T_{a}} \frac{e_{h}}{e_{q h}} q-\left[\frac{K_{p}}{T_{a}}\left(e_{x}-\frac{e_{h}}{e_{q h}} e_{q x}-e_{g}\right)+K_{i}\right] x-\frac{K_{p}}{T_{a}}\left(e_{y}-\frac{e_{h}}{e_{q h}} e_{q y}\right) y+\frac{K_{p}}{T_{a}} m_{g} \\
q^{\prime}=\frac{-\left(\frac{2 h_{f}}{H_{0}}+\frac{\lambda Q_{0}}{H_{0} c B}+\frac{1}{e_{q h}}\right) q+\frac{e_{q x}}{e_{q h}} x+\frac{e_{q y}}{e_{q h}} y}{\frac{\lambda Q_{0} V_{x}}{g H_{0} c B \tan \alpha} q+T_{w s}}
\end{array}\right.
$$

\section{The hydro-turbine governing system with pressurized flow}

\section{tailrace}

For the pressurized flow tailrace, two representative models are established. 
From Eq. (2) and (6)-(9), two nonlinear dynamic models of the hydro-turbine governing system with pressurized flow tailrace are established.

The first model considers the effect of the time constant of steady state flow $T_{w s}$. The dynamic equation of the penstock in hydropower station with pressurized flow tailrace is obtained from Eq. (2). The first model considering the influence of $T_{w s}$ is

$$
\left\{\begin{array}{l}
x^{\prime}=\frac{1}{T_{a}}\left[\frac{e_{h}}{e_{q h}} q+\left(e_{x}-\frac{e_{h}}{e_{q h}} e_{q x}-e_{g}\right) x+\left(e_{y}-\frac{e_{h}}{e_{q h}} e_{q y}\right) y-m_{g}\right] \\
y^{\prime}=-\frac{K_{p}}{T_{a}} \frac{e_{h}}{e_{q h}} q-\left[\frac{K_{p}}{T_{a}}\left(e_{x}-\frac{e_{h}}{e_{q h}} e_{q x}-e_{g}\right)+K_{i}\right] x-\frac{K_{p}}{T_{a}}\left(e_{y}-\frac{e_{h}}{e_{q h}} e_{q y}\right) y+\frac{K_{p}}{T_{a}} m_{g} . \\
q^{\prime}=\frac{1}{T_{w s}}\left(\frac{e_{q x}}{e_{q h}} x+\frac{e_{q y}}{e_{q h}} y-\frac{q}{e_{q h}}-\frac{2 h_{f}}{H_{0}} q\right)
\end{array}\right.
$$

The change of flow inertia $T_{w x}$ is considered in the second model. Then the dynamic equation of the penstock can be written as

$$
h=-\left(T_{w s}+T_{w x}\right) \frac{d q}{d t}-\frac{2 h_{f}}{H_{0}} q
$$

The second model considering the change of flow inertia $T_{w x}$ can be obtained as:

$$
\left\{\begin{aligned}
x^{\prime}= & \frac{1}{T_{a}}\left[\frac{e_{h}}{e_{q h}} q+\left(e_{x}-\frac{e_{h}}{e_{q h}} e_{q x}-e_{g}\right) x+\left(e_{y}-\frac{e_{h}}{e_{q h}} e_{q y}\right) y-m_{g}\right] \\
y^{\prime}= & -\frac{K_{p}}{T_{a}} \frac{e_{h}}{e_{q h}} q-\left[\frac{K_{p}}{T_{a}}\left(e_{x}-\frac{e_{h}}{e_{q h}} e_{q x}-e_{g}\right)+K_{i}\right] x-\frac{K_{p}}{T_{a}}\left(e_{y}-\frac{e_{h}}{e_{q h}} e_{q y}\right) y+\frac{K_{p}}{T_{a}} m_{g} \\
& -\left(\frac{2 h_{f}}{H_{0}}+\frac{1}{e_{q h}}\right) q+\frac{e_{q x}}{e_{q h}} x+\frac{e_{q y}}{e_{q h}} y \\
q^{\prime}= & \frac{\lambda Q_{0} V_{x}}{g H_{0} c B \tan \alpha} q+T_{w s}
\end{aligned}\right.
$$

\section{The nonlinear dynamic expression of hydro-turbine transfer coefficients}

Transfer coefficients change with the operation condition, which has important effect on the stability of hydro-turbine governing systems during transient processes 
(Zhang, Chen, Xu \& Wang, 2015; Zhang, Chen, Wu, Wang, Lee \& Jung, 2017; Zeng, Yang, Tang \& Yang, 2016). Previous research on the transient stability analysis of the hydro-turbine governing system used fixed transfer coefficients to describe transient performance. This may result in the inaccurate results during transient processes (Zhang, Cheng, Xia, Yang \& Qian, 2016; Yang, Norrlund, Saarinen, Yang, Guo \& Zeng, 2016; Li \& Zhou, 2011; Ling \& Tao, 2006). To better describe the transient performance of the hydro-turbine governing system, dynamic transfer coefficients considering the load variations are introduced to investigate the transient stability of the system.

Transfer coefficients change with operation conditions (Zhang, Chen, Xu \& Wang, 2015). The relationships between the relative unit power (P) and the transfer coefficients are shown in Fig. 2 (Zhang, Chen, Xu \& Wang, 2015).
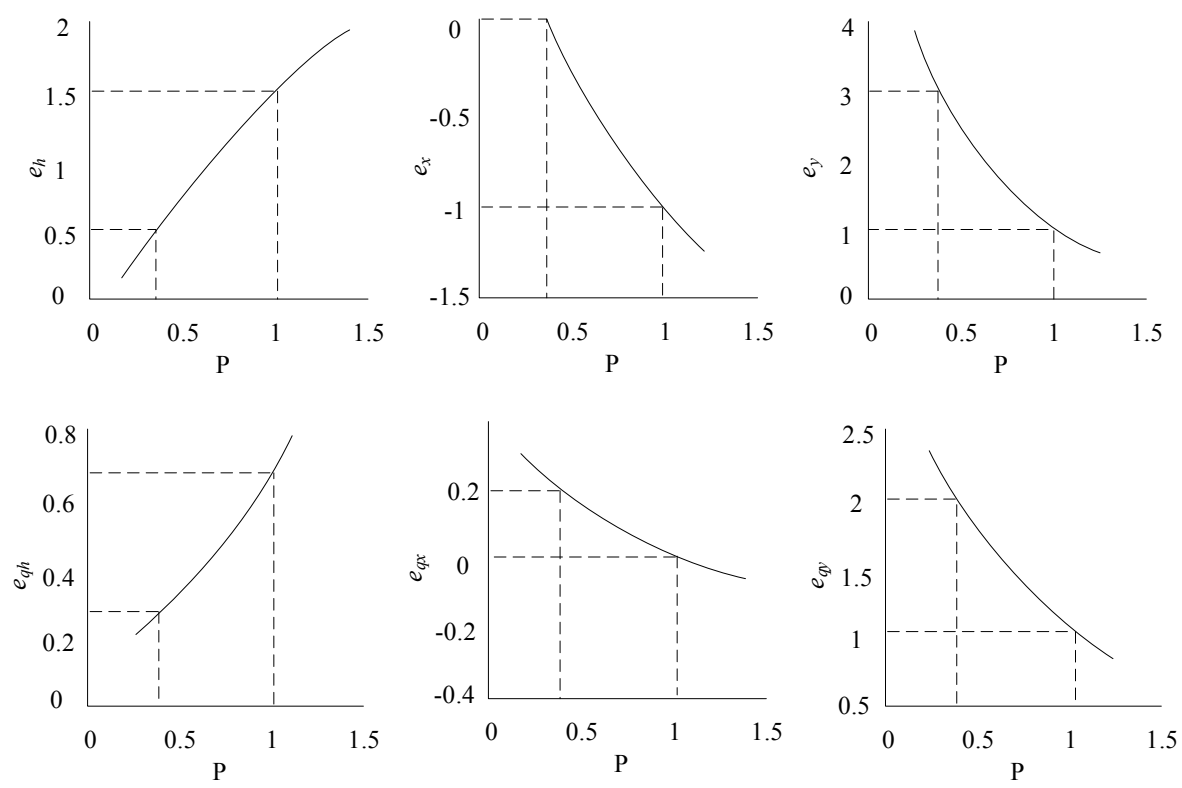

Figure 2 Curves of hydro-turbine transfer coefficients.

The load changes within $10 \%$ of the rated load during the small fluctuation 
processes and the cyclical change of the load is the common form during the transient processes. In order to analyze the transient process of load fluctuation, we assume that the relationship between the load variation and time $t$ is considered as

$$
m_{g}=0.1 \sin (\pi t)
$$

where $m_{g}$ denotes the relative derivation of resisting moment and the scaled resisting moment is the scaled load.

The transfer coefficients of the hydro-turbine under the rated condition are as follows (Romero-Gomez \& Richmond, 2017):

$$
e_{h}=1.5, e_{x}=-1, e_{y}=1, e_{q h}=0.5, e_{q x}=0, e_{q y}=1
$$

The transfer coefficients are always changing during the transient processes and the changing rules are related to the load variations. Based on the initial values of the transfer coefficients and the load fluctuation, we assume that the dynamic transfer coefficients expressions during the load fluctuation process are presented as follows:

$$
\begin{aligned}
& e_{h}=1.5+0.15 \sin (\pi t), \\
& e_{x}=-1-0.1 \sin (\pi t), \\
& e_{y}=1-0.1 \sin (\pi t), \\
& e_{q h}=0.5+0.05 \sin (\pi t), \\
& e_{q x}=-0.1 \sin (\pi t), \\
& e_{q y}=1-0.1 \sin (\pi t) .
\end{aligned}
$$

The hydro-turbine governing system is a time-varying system during transient processes. In order to describe dramatic changes of its transient performance, dynamic expressions of the transfer coefficients considering the load variations are introduced for the stability analysis of the system during transient processes. Substituting Eq. 
(15)-(20) into Eq. (10), the nonlinear transient model of the hydro-turbine governing system with inclined ceiling tailrace during the load fluctuation process can be obtained:

$$
\left\{\begin{array}{l}
x^{\prime}=\frac{1}{T_{a}}\left[\frac{(1.5+0.15 \sin (\pi t))}{(0.5+0.05 \sin (\pi t))} q+\left((-1-0.1 \sin (\pi t))-\frac{(1.5+0.15 \sin (\pi t))}{(0.5+0.05 \sin (\pi t))}(-0.1 \sin (\pi t))-e_{g}\right) x\right. \\
\left.+\left((1-0.1 \sin (\pi t))-\frac{(1.5+0.15 \sin (\pi t))}{(0.5+0.05 \sin (\pi t))}(1-0.1 \sin (\pi t))\right) y-m_{g}\right] \\
y^{\prime}=-\frac{K_{p}}{T_{a}} \frac{(1.5+0.15 \sin (\pi t))}{(0.5+0.05 \sin (\pi t))} q-\left[\frac{K_{p}}{T_{a}}\left((-1-0.1 \sin (\pi t))-\frac{(1.5+0.15 \sin (\pi t))}{(0.5+0.05 \sin (\pi t))}(-0.1 \sin (\pi t))-e_{g}\right)+K_{i}\right] x \\
-\frac{K_{p}}{T_{a}}\left((1-0.1 \sin (\pi t))-\frac{(1.5+0.15 \sin (\pi t))}{(0.5+0.05 \sin (\pi t))}(1-0.1 \sin (\pi t))\right) y+\frac{K_{p}}{T_{a}} m_{g} \\
\quad-\left(\frac{2 h_{f}}{H_{0}}+\frac{\lambda Q_{0}}{H_{0} c B}+\frac{1}{(0.5+0.05 \sin (\pi t))}\right) q+\frac{(-0.1 \sin (\pi t))}{(0.5+0.05 \sin (\pi t))} x+\frac{(1-0.1 \sin (\pi t))}{(0.5+0.05 \sin (\pi t))} y \\
q^{\prime}=\frac{\lambda Q_{0} V_{x}}{g H_{0} c B \tan \alpha} q+T_{w s}
\end{array}\right.
$$

Similarly, the nonlinear transient model of governing system with pressurized flow tailrace can be got as

$$
\left\{\begin{array}{l}
x^{\prime}=\frac{1}{T_{a}}\left[\frac{(1.5+0.15 \sin (\pi t))}{(0.5+0.05 \sin (\pi t))} q+\left((-1-0.1 \sin (\pi t))-\frac{(1.5+0.15 \sin (\pi t))}{(0.5+0.05 \sin (\pi t))}(-0.1 \sin (\pi t))-e_{g}\right) x\right. \\
\left.+\left((1-0.1 \sin (\pi t))-\frac{(1.5+0.15 \sin (\pi t))}{(0.5+0.05 \sin (\pi t))}(1-0.1 \sin (\pi t))\right) y-m_{g}\right] \\
y^{\prime}=-\frac{K_{p}}{T_{a}} \frac{(1.5+0.15 \sin (\pi t))}{(0.5+0.05 \sin (\pi t))} q-\left[\frac{K_{p}}{T_{a}}\left((-1-0.1 \sin (\pi t))-\frac{(1.5+0.15 \sin (\pi t))}{(0.5+0.05 \sin (\pi t))}(-0.1 \sin (\pi t))-e_{g}\right)+K_{i}\right] x \\
-\frac{K_{p}}{T_{a}}\left((1-0.1 \sin (\pi t))-\frac{(1.5+0.15 \sin (\pi t))}{(0.5+0.05 \sin (\pi t))}(1-0.1 \sin (\pi t))\right) y+\frac{K_{p}}{T_{a}} m_{g} \\
q^{\prime}=\frac{1}{T_{\text {ws }}}\left(\frac{(-0.1 \sin (\pi t))}{(0.5+0.05 \sin (\pi t))} x+\frac{(1-0.1 \sin (\pi t))}{(0.5+0.05 \sin (\pi t))} y-\frac{q}{(0.5+0.05 \sin (\pi t))}-\frac{2 h_{f}}{H_{0}} q\right)
\end{array}\right.
$$

The model of the system with pressurized flow tailrace and additional flow inertia can be written as 


$$
\left\{\begin{array}{l}
x^{\prime}=\frac{1}{T_{a}}\left[\frac{(1.5+0.15 \sin (\pi t))}{(0.5+0.05 \sin (\pi t))} q+\left((-1-0.1 \sin (\pi t))-\frac{(1.5+0.15 \sin (\pi t))}{(0.5+0.05 \sin (\pi t))}(-0.1 \sin (\pi t))-e_{g}\right) x\right. \\
\left.+\left((1-0.1 \sin (\pi t))-\frac{(1.5+0.15 \sin (\pi t))}{(0.5+0.05 \sin (\pi t))}(1-0.1 \sin (\pi t))\right) y-m_{g}\right] \\
y^{\prime}=-\frac{K_{p}}{T_{a}} \frac{(1.5+0.15 \sin (\pi t))}{(0.5+0.05 \sin (\pi t))} q-\left[\frac{K_{p}}{T_{a}}\left((-1-0.1 \sin (\pi t))-\frac{(1.5+0.15 \sin (\pi t))}{(0.5+0.05 \sin (\pi t))}(-0.1 \sin (\pi t))-e_{g}\right)+K_{i}\right] x \\
-\frac{K_{p}}{T_{a}}\left((1-0.1 \sin (\pi t))-\frac{(1.5+0.15 \sin (\pi t))}{(0.5+0.05 \sin (\pi t))}(1-0.1 \sin (\pi t))\right) y+\frac{K_{p}}{T_{a}} m_{g} \\
\quad-\left(\frac{2 h_{f}}{H_{0}}+\frac{1}{(0.5+0.05 \sin (\pi t))}\right) q+\frac{(-0.1 \sin (\pi t))}{(0.5+0.05 \sin (\pi t))} x+\frac{(1-0.1 \sin (\pi t))}{(0.5+0.05 \sin (\pi t))} y \\
q^{\prime}=\frac{\lambda Q_{0} V_{x}}{g H_{0} c B \tan \alpha} q+T_{w s}
\end{array}\right.
$$

\section{Numerical experiment}

In this paper, we use bifurcation diagram to investigate the effect of load fluctuation on the stability of the system with different kinds of tailrace tunnels.

Definition of bifurcation curve: The crest of system parameter $(q)$ in time waveforms is selected as the point of bifurcation curve. These points form the bifurcation curve with the change of bifurcation parameter $\left(m_{\mathrm{g}}\right)$.

The bifurcation parameter $m_{g}(t)$ is shown on the horizontal axis of the plot and the vertical axis shows the set of values of the turbine discharge visited asymptotically from almost all initial condition. The fluctuation of the vertical axis parameter can reflect the dynamic characteristics of the system. The greater fluctuation, and the worse system stability. Figures. 3-5 and 7 are bifurcation diagrams of the systems, obtained by solving the differential equations and using Get-Max method to take points in MATLAB. Figure. 6 is obtained by adopting the Runge-Kutta method with a fixed time step of 0.1 and 2000 iteration steps. The initial condition of the hydro-turbine system is rated condition and $(x, y, q)$ refer to the relative deviations of the corresponding variables. Therefore, we assume that the initial condition is $(x, y, q)$ $=(0.001,0.001,0.001)$.

The considered system parameters are as follows

$$
\begin{aligned}
& H_{0}=70.7 \mathrm{~m}, Q_{0}=466.7 \mathrm{~m}^{3} \mathrm{~s}^{-1}, T_{a}=8.77 \mathrm{~s}, \quad B=10.0 \mathrm{~m}, \lambda=3, T_{w s}=3.20 \mathrm{~s}, \\
& h_{f}=2.68 \mathrm{~m}, H_{x}=23 \mathrm{~m}, \tan \alpha=0.03, K_{p}=3, K_{i}=0.3
\end{aligned}
$$

Figures. 3-5 show the global bifurcation diagrams of the systems with inclined 
ceiling tailrace, pressurized flow tunnel and pressurized flow tunnel considering flow inertia, respectively. The bifurcation parameter is the relative deviation of the resistive torque during the transient time $(t)$ from 0 s to $2 \mathrm{~s}$.

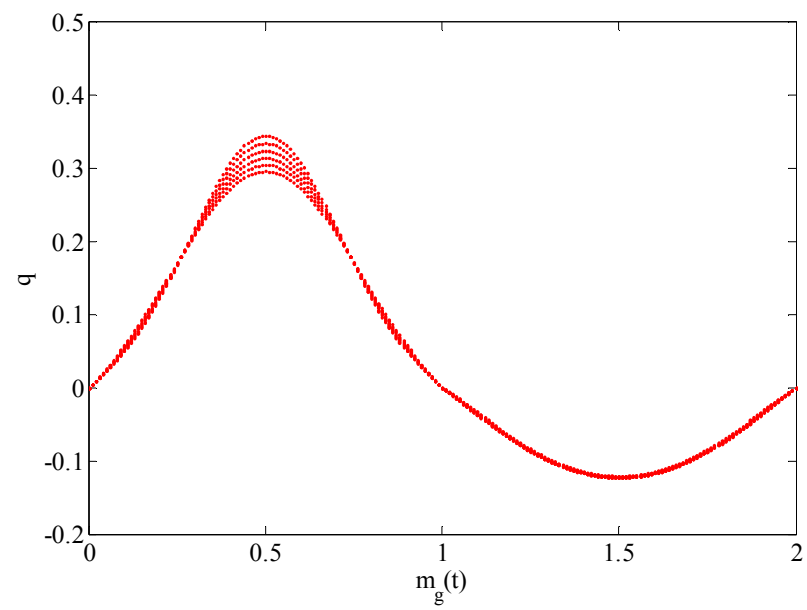

Figure 3 Bifurcation diagram of turbine discharge for the system with inclined ceiling tailrace $(0 \leq t \leq 2 \mathrm{~s})$

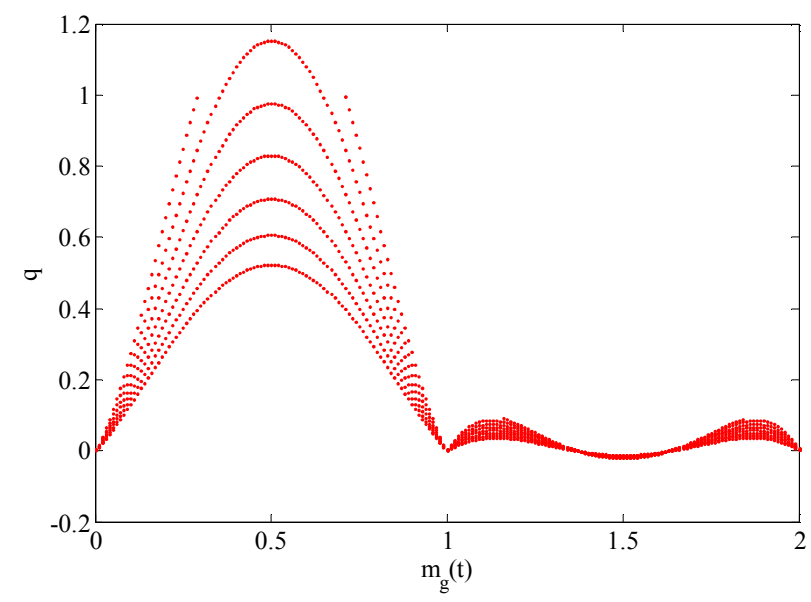

Figure 4 Bifurcation diagram of turbine discharge for the system with pressurized flow tunnel $(0 \leq t \leq 2 \mathrm{~s})$ 


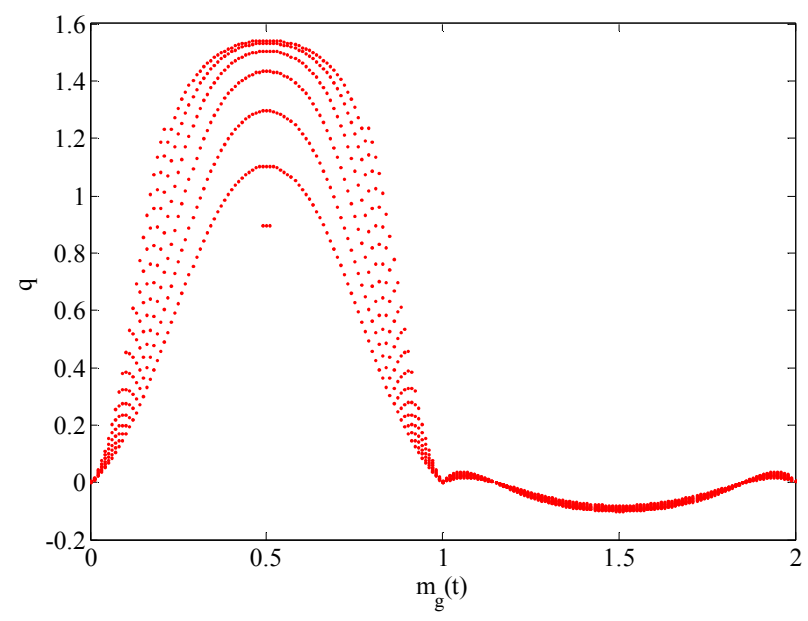

Figure 5 Bifurcation diagram of turbine discharge for the system with pressurized flow tunnel and flow inertia $(0 \leq t \leq 2 \mathrm{~s})$

From Fig. 3, it can be seen that the relative deviation of the turbine discharge shows periodic fluctuation during the load fluctuation process. For each time point, the system shows constant amplitude vibration except in the regions $0.3-0.7$ and 2.3-2.7. The maximum and minimum of the relative deviation of the turbine discharge are 0.35 and -0.13 , respectively. It deserves to note that the absolute maximum of the relative deviation of the turbine discharge during the load increase process is about three times that during the load decrease process. This is detrimental for the stability of the system and the load increase process is worth to attention.

It can be seen from Fig. 4 that the relative deviation of the turbine discharge shows unstable vibration during the load fluctuation process, especially the load increase process. The maximum of the relative deviation of the turbine discharge is 1.19 during the load increase process and there is positive-negative conversion of the turbine discharge during the load decrease process. These results indicate that the stability of the systems with pressurized flow tunnels is poorer compared with system with inclined ceiling tailrace.

Fig. 5 shows responses of the relative deviation of the turbine discharge similar to system with pressurized flow tunnel (Fig. 4). The maximum of the relative deviation of the turbine discharge is 1.51 during the load increase process. The results show that systems with pressurized flow tunnels are characterized by a better stability 
than those with pressurized flow tunnels and flow inertia.

Overall, systems with inclined ceiling tailrace show better stability compared with other solutions. These results from numerical analysis can be explained by the following theoretical analysis.

From Eq. (5), the dynamic equation of the penstock in hydropower station with inclined ceiling tailrace can be obtained as follows:

$$
h=-\left(T_{w s}+T_{w x}\right) \frac{d q}{d t}-\frac{2\left(h_{f}+\frac{\lambda Q_{0}}{2 c B}\right)}{H_{0}} q
$$

By comparing the Eq. (24) with Eq. (2), the change of the flow inertia $\left(T_{w x}\right)$ of hydropower stations with inclined ceiling tailrace is added to the pressurized flow inertia $\left(T_{w s}\right)$. This means that the tailrace tunnel with sloping ceiling can change the flow inertia of the conduit system. The larger the flow inertia of the conduit system is, the poorer stability of the system is. Therefore, the flow inertia of the conduit system ( $T_{w s}+T_{w x}$ ) will decrease, if the $T_{w x}$ is negative caused by the load adjustment, which is beneficial for the stability of the system. On the contrary, when the $T_{w x}$ is positive resulting from the load adjustment, the flow inertia of the conduit system will increase, which causes harm to the stability of the system.

On the other hand, the water level fluctuation of the free flow $\left(z_{y}=\frac{\lambda Q_{0}}{H_{0} c B} q\right)$ can change the head loss of the system. The effects of the water level fluctuation and head loss can be shown as $h_{f}+\lambda Q_{0} /(2 c B)$. For the hydropower station without surge tank, the larger the head loss of penstock is, the better the stability of the system is. As the $\lambda Q_{0} /(2 c B)$ is always positive, the water level fluctuation of the free flow in the tailrace tunnel with sloping ceiling always increases the head loss of the system. Therefore, the water level fluctuation of the free flow is beneficial to the stability of the system regardless of the load increase or decrease. From the above analysis, the system with inclined ceiling tailrace can get the best stability among the three tailrace 
systems when the change of flow inertia $\left(T_{w x}\right)$ is negative caused by the load adjustment. The stability of the system with pressurized flow tunnel and flow inertia is the poorest, if the change of flow inertia $\left(T_{w x}\right)$ is positive resulting from the load adjustment. In addition, if the effect of the water level fluctuation $\left(z_{y}\right)$ is stronger than that of the flow inertia $\left(T_{w x}\right)$, even if the $T_{w x}$ is positive, the stability of the system with inclined ceiling tailrace is better than that with pressurized flow tunnel.

$L_{\mathrm{x}}$ and $Z_{\mathrm{y}}$ denote the relative distance of the free surface-pressure flow and the water level, respectively. In this paper, $L_{x}=\frac{\lambda Q_{0}}{c B \tan \alpha} q, \quad z_{y}=\frac{\lambda Q_{0}}{H_{0} c B} q$ and $T_{w x}=\frac{\lambda Q_{0}}{g H_{0} c B \tan \alpha} q$. Thus, $T_{w x}=\frac{L_{x}}{g H_{0}}=T_{w x}=\frac{z_{y}}{g \tan \alpha} . L_{\mathrm{x}}$ and $Z_{\mathrm{y}}$ can be described by $T_{w x}$ which is the transient inertia of the flow. To analyze the changing rules of $L_{\mathrm{x}}$ and $Z_{\mathrm{y}}$ and verify the correctness of the theoretical analysis, two representative points during load deviations are analyzed as follows (i.e. $m_{g}=0.1$ and $m_{g}=-0.1$ )

(a)

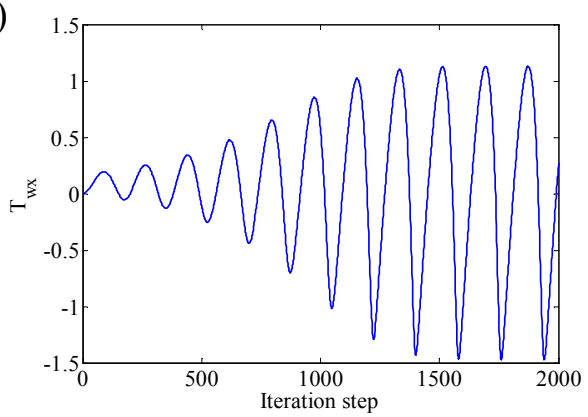

(b)

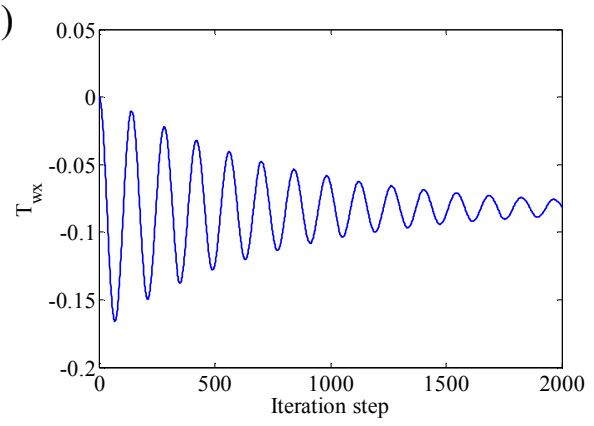

Figure 6 Time waveforms of the transient flow inertia with inclined ceiling tailrace (iteration step=2000). (a) time waveforms of $T_{w x}$ for $m_{g}=0.1$, (b) time waveforms of $T_{w x}$ for $m_{g}=-0.1$

Fig. 6 shows the responses of the transient flow inertia during transient processes. For $t=0.5 \mathrm{~s}$ and $m_{g}=0.1$, the flow inertia fluctuates within the range $-1.5 \sim 1$. While for $t=1.5 \mathrm{~s}$, and $m_{g}=-0.1$, the change of flow inertia is always negative. 
These results indicate that the change of transient flow inertia $\left(T_{w x}\right)$ may be positive resulting from the increase of the load and it is always negative if the load is decreasing. Positive changes of transient flow inertia are bad for the stability of the system while negative changes always improve the stability of the system. From Figs. $3,6 \mathrm{a}$ and $6 \mathrm{~b}$, the absolute value of the relative deviation of the flow at $t=0.5 \mathrm{~s}$ is much bigger than that at $t=1.5 \mathrm{~s}$, which can prove that the positive value of transient flow inertia is detrimental to the system and the negative value of transient flow inertia can improve the stability of the system. These results can prove the correctness of the theoretical analysis.

The gradient of the inclined ceiling tailrace is the key factor affecting the relationship between flow inertia and water level fluctuation (Guo, Yang, Chen \& Teng, 2014). Therefore, for different gradients of the inclined ceiling tailrace, the bifurcation diagrams of hydro-turbine governing system are presented to analyze the effect of the gradient on the dynamic characteristics of the system during the load fluctuation process.

(a)

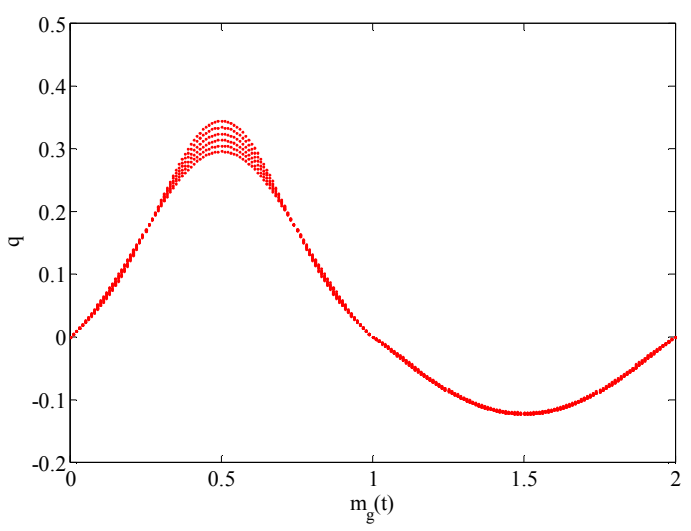

(b)

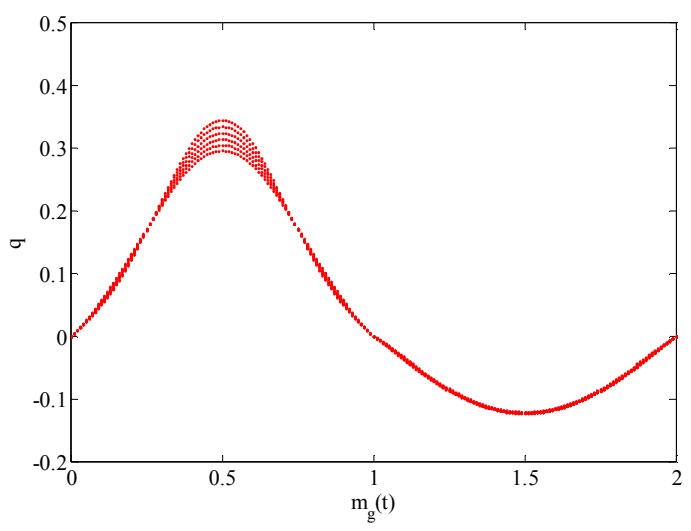




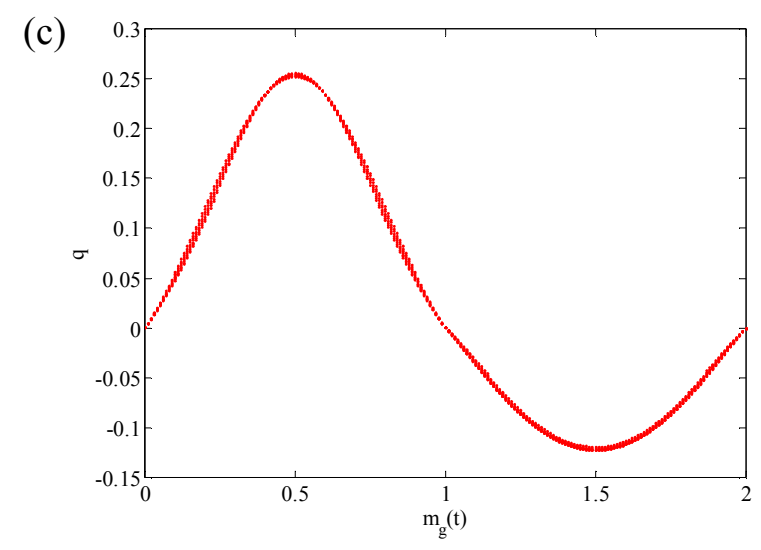

Figure 7 Bifurcation diagrams of the system with different gradients of the inclined ceiling tailrace. (a) $\tan \alpha=0.02$, (b) $\tan \alpha=0.03$, (c) $\tan \alpha=0.04$

Fig. 7 shows the responses of the system with different gradients of the inclined ceiling tailrace. The turbine discharge performs similar tendency during the load fluctuation process for the inclined ceiling tailrace with different gradients. For $\tan \alpha=0.02,0.03$ and 0.04 , the ranges of the relative deviation of the turbine discharge are $-0.15 \sim 0.63,-0.14 \sim 0.35$ and $-0.12 \sim 0.26$, respectively. In addition, the turbine discharge shows multi-frequency vibrations when $\tan \alpha=0.02$ and 0.03 , while they disappear when $\tan \alpha=0.04$. This means that the increase of the gradient can reduce the amplitude of turbine discharge and improve its transient performance. These results indicate that the stability of the system can be improved by increasing the gradient of the inclined ceiling tailrace.

\section{Conclusions}

The transient stability of the hydro-turbine governing system with three kinds of tailrace tunnels is investigated in this paper. The dynamic models of the hydro-turbine governing system are developed for stability analysis during transient processes by introducing dynamic transfer coefficients. 
Bifurcation diagrams of the systems indicate that the stability of the system with inclined ceiling tailrace is the best among the three considered tailrace systems. Simulation results show that load increasing leads to positive values of the flow inertia. Otherwise, the flow inertia is negative. In addition, the increase of the gradient can further improve the stability of the system.

The theoretical results indicate that negative values of flow inertia are beneficial for the stability of the system. Otherwise, it has the opposite effect. The water level variations are always good for the system stability during the transient processes. Theoretical results are consistent with the simulation results.

The combined layout of the tailrace surge tank and tailrace tunnel with sloping ceiling will be studied to improve the transient stability and reduce the construction costs of hydropower stations.

$$
\begin{array}{ll}
\text { Notation } & \\
B & =\text { Width of sloping ceiling tailrace tunnel (m) } \\
c & =\text { Water velocity of free surface flow section }\left(\mathrm{ms}^{-1}\right) \\
e_{h}, e_{x}, e_{y} & =\text { Moment transfer coefficients of turbine (-) } \\
e_{q h}, e_{q x}, e_{q y} & =\text { Discharge transfer coefficients of turbine (-) } \\
e_{g} & =\text { Self-regulation coefficient of load (-) } \\
f & =\text { Sectional area of penstock (m²) } \\
g & \left.=\text { Acceleration of gravity (ms }{ }^{-2}\right) \\
H & =\text { Head loss in penstock (m) } \\
h_{f} & =\text { Water depth at interface of free surface-pressurized flow (m) } \\
H_{x} &
\end{array}
$$


$K_{i} \quad=$ Integral adjustment coefficient (s)

$K_{p} \quad=$ Proportional adjustment coefficient (-)

$L \quad=$ Length of penstock (m)

$L_{x} \quad=$ Relative distance of the free surface-pressurized flow (m)

$m_{g} \quad=$ Relative derivation of resisting moment (-)

$M_{g} \quad=$ Resisting moment $(\mathrm{N} \cdot \mathrm{m})$

$m_{t} \quad=$ Relative derivation of kinetic moment (-)

$M_{t} \quad=$ Kinetic moment $(\mathrm{N} \cdot \mathrm{m})$

$n \quad=$ Tuebine speed $(\mathrm{r} / \mathrm{min})$

$Q \quad=$ Hydro-turbine unit discharge $\left(\mathrm{m}^{3} \mathrm{~s}^{-1}\right)$

$T_{a} \quad=$ Hydro-turbine unit inertia time constant (s)

$T_{w s} \quad=$ Steady-state flow inertia time constant of penstock (s)

$T_{w x} \quad=$ Transient-state flow inertia time constant of penstock (s)

$V \quad=$ Flow velocity in penstock $\left(\mathrm{ms}^{-1}\right)$

$Y \quad=$ Guide vane opening $(\mathrm{m})$

$Z_{y} \quad=$ Water level in open channel (m)

$\alpha \quad=$ Ceiling slope angle of sloping ceiling tailrace tunnel (rad)

$\lambda \quad=$ Cross-sectional coefficient of tailrace tunnel (-)

\section{Funding}

This work was supported by the scientific research foundation of National Natural Science Foundation of China--Outstanding Youth Foundation (No. 51622906), National Natural Science Foundation of China (No. 51479173), Fundamental Research Funds for the Central Universities (No. 201304030577), Scientific research funds of Northwest A\&F University (No. 2013BSJJ095), Science Fund for Excellent Young Scholars from Northwest A\&F University and Shaanxi Nova program (No. 2016KJXX-55).

\section{References}


Anup, K. C., Lee, Y. H., \& Thapa, B. (2016). CFD study on prediction of vortex shedding in draft tube of Francis turbine and vortex control techniques. Renewable Energy, 88, 1406-1421.

Cheng, Y. G., Li J. P., \& Yang J. D. (2007). Free surface-pressurized flow in ceiling-sloping tailrace tunnel of hydropower plant: simulation by VOF model. Journal of Hydraulic Research, 45, 88-99.

Chen, D. Y., Ding, C., Ma, X. Y., Yuan, P., \& Ba, D. D. (2013). Nonlinear dynamical analysis of hydro-turbine governing system with a surge tank. Applied Mathematical Modelling, 37, 7611-7623.

Chitrakar, S., Neopane, H. P., \& Dahlhaug, O. G. (2016). Study of the simultaneous effects of secondary flow and sediment erosion in Francis turbines. Renewable Energy, 97, 881-891.

Ciocan, T., Susan-Resiga, R. F., \& Muntean, S. (2016). Modelling and optimization of the velocity profiles at the draft tube inlet of a Francis turbine within an operating range. Journal of Hydraulic Research, 54, 74-89.

Fecarotta, O., Carravetta, A., Ramos, H. M., \& Martino, R. (2016). An improved affinity model to enhance variable operating strategy for pumps used as turbines. Journal of Hydraulic Research, 54, 332-341.

Guo, W. C., Yang, J. D., Chen, J. P., \& Teng, Y. (2014). Effect mechanism of penstock on stability and regulation quality of turbine regulating system. Mathematical Problems in Engineering, doi: 10.1155/2014/349086.

Khan, A. A, Shahzad, A., Hayat, I., \& Miah, M. S. (2016). Recovery of flow conditions for optimum electricity generation through micro hydro turbines. Renewable Energy, 96, 940-948.

Kim, J. W., Jo, I. C., Park, J. H., Shin, Y., \& Chung, J. T. (2017). Theoretical method of selecting number of buckets for the design and verification of a Pelton turbine. Journal of Hydraulic Research, 55, 695-705.

Lai, X., Chen, J. Z., \& Yang, J. D. (2001). Stability analysis of hydropower station with inclined ceiling tailrace. Journal of Hydropower Electric Engineering, 4, 102-107. (in Chinese) 
Li, Z. J., Bi, H. L., Karney, B., Wang, Z. W., \& Yao, Z. (2017). Three-dimensional transient simulation of a prototype pump-turbine during normal turbine shutdown. Journal of Hydraulic Research, 55, 520-537.

Li, H. H., Chen, D. Y., Zhang, H., Wu, C. Z., \& Wang, X. Y. (2017). Hamiltonian analysis of a hydro-energy generation system in the transient of sudden load increasing. Applied Energy, 185, 244-253.

Li, C. S., \& Zhou, J. Z. (2011). Parameters identification of hydraulic turbine governing system using improved gravitational search algorithm. Energy Conversion and Management, 52, 374-381.

Ling, D. J., \& Tao, Y. (2006). An analysis of the Hopf bifurcation in a hydroturbine governing system with saturation. IEEE Transactions on Energy Conversion, 21, $512-515$.

Romero-Gomez, P., \& Richmond, M. C. (2017). Movement and collision of Lagrangian particles in hydro-turbine intakes: acasestudy. Journal of Hydraulic Research, 55, 706-720.

Shimokawa, K., Furukawa, A., Okuma, K., Matsushita, D., \& Watanabe, S. (2012). Experimental study on simplification of Darrieus-type hydro turbine with inlet nozzle for extra-low head hydropower utilization. Renewable Energy, 41, 376-382.

Skripkin, S., Tsoy, M., Shtork, S., \& Hanjalic, K. (2016). Comparative analysis of twin vortex ropes in laboratory models of two hydro-turbine draft-tubes. Journal of Hydraulic Research, 54, 450-460.

Wei, X. Z., Su, W. T., Li, X. B., Li, F. C., \& Guo, L. (2014). Effect of blade perforation on Francis hydro-turbine cavitation characteristics. Journal of Hydraulic Research, 52, 412-420.

Xu, B. B., Wang, F. F., Chen, D. Y., \& Zhang, H. (2016). Hamiltonian modeling of multi-hydro-turbine governing systems with sharing common penstock and dynamic analyses under shock load. Energy Conversion and Management, 108, 478-487.

Guo, W. C., Yang, J. D., Wang, M. J., \& Lai, X. (2015). Nonlinear modeling and 
stability analysis of hydro-turbine governing system with sloping ceiling tailrace tunnel under load disturbance. Energy Conversion and Management, 106, $127-138$.

Yang, W. J., Norrlund, P., Saarinen, L., Yang, J. D., Guo, W. C., \& Zeng, W. (2016). Wear and tear on hydro power turbines - Influence from primary frequency control. Renewable Energy, 87, 88-95.

Zeng, Y., Guo, Y. K., Zhang, L. X., Xu, T. M., \& Dong, H. K. (2013). Nonlinear hydro turbine model having a surge tank. Mathematical and Computer Modelling of Dynamical Systems, 19, 12-28.

Zeng, W., Yang, J. D., Tang, R. B., \& Yang, W. J. (2016). Extreme water-hammer pressure during one-after-another load shedding in pumped-storage stations. Renewable Energy, 99, 35-44.

Zhang, H., Chen, D. Y., Xu, B. B., \& Wang, F. F. (2015). Nonlinear modeling and dynamic analysis of hydro-turbine governing ystem in the process of load rejection transient. Energy Conversion and Management, 90, 128-137.

Zhang, H., Chen, D. Y., Wu, C. Z., Wang, X. Y., Lee, J. M., \& Jung, K. H. (2017). Dynamic modeling and dynamical analysis of pump-turbines in S-shaped regions during runaway operation. Energy Conversion and Management, 138, 375-382.

Zhang, X. X., Cheng, Y. G., Xia, L. S., Yang, J. D., \& Qian, Z. D. (2016). Looping dynamic characteristics of a pump-turbine in the S-shaped region during runaway. Journal of Fluids Engineering-Transactions of the ASME, 138, 091102.

\section{Figures with captions}

Figure 1 Hydropower station with inclined ceiling tailrace

Figure 2 Curves of hydro-turbine transfer coefficient

Figure 3 Bifurcation diagram of turbine discharge for the system with inclined ceiling tailrace $(0 \leq t \leq 2 \mathrm{~s})$

Figure 4 Bifurcation diagram of turbine discharge for the system with pressurized flow tunnel $(0 \leq t \leq 2 \mathrm{~s})$ 
Figure 5 Bifurcation diagram of turbine discharge for the system with pressurized flow tunnel and flow inertia $(0 \leq t \leq 2 \mathrm{~s})$

Figure 6 Time waveforms of the transient flow inertia with inclined ceiling tailrace (Iteration step=2000). (a) time waveforms of $T_{w x}$ for $m_{g}=0.1$, (b) time waveforms of $T_{w x}$ for $m_{g}=-0.1$

Figure 7 Bifurcation diagrams of the system with different gradients of the inclined ceiling tailrace. (a) $\tan \alpha=0.02$, (b) $\tan \alpha=0.03$, (c) $\tan \alpha=0.04$ 


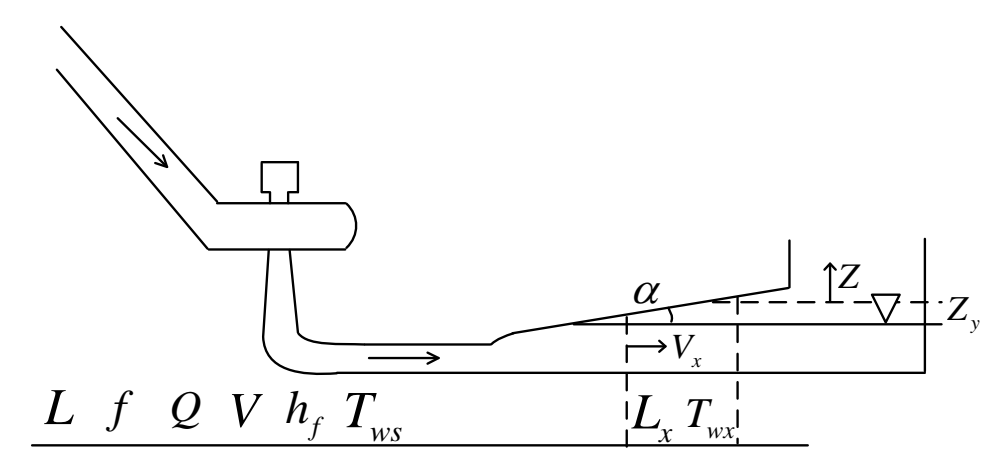



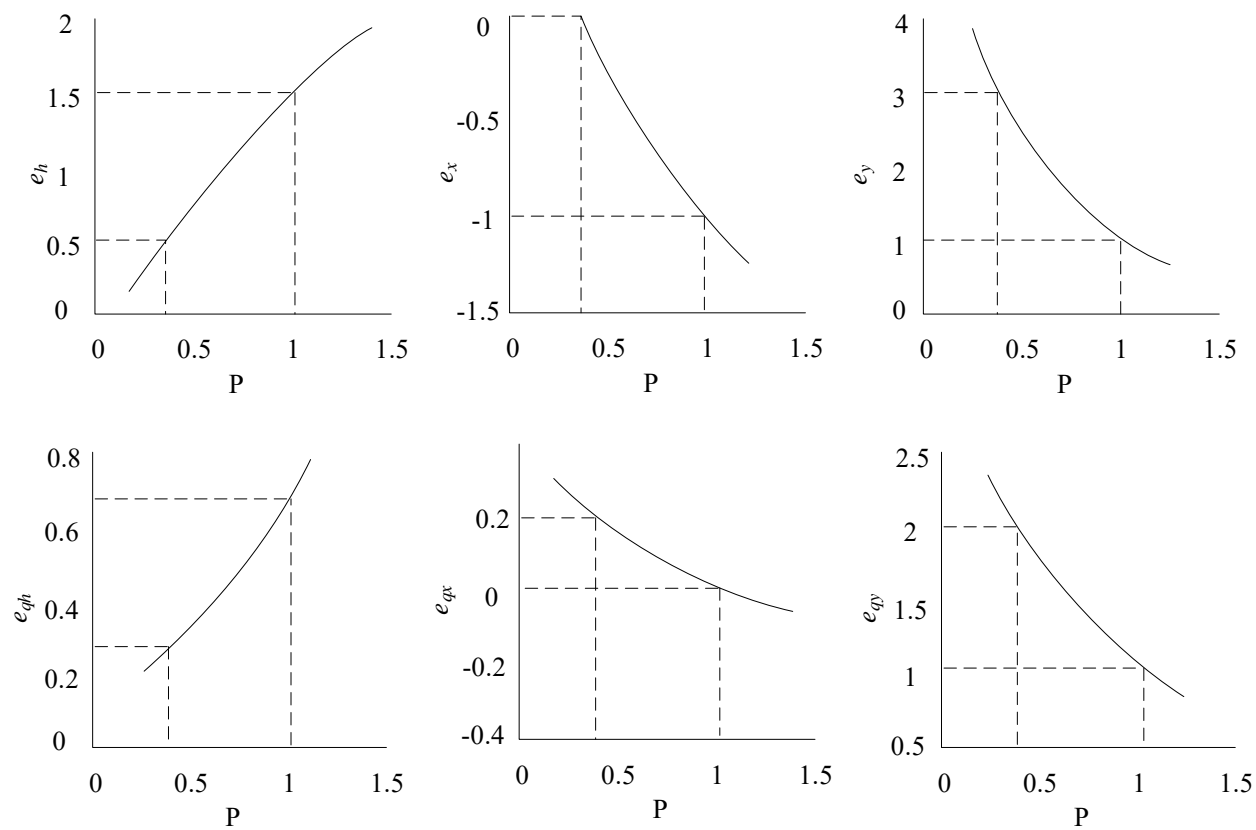


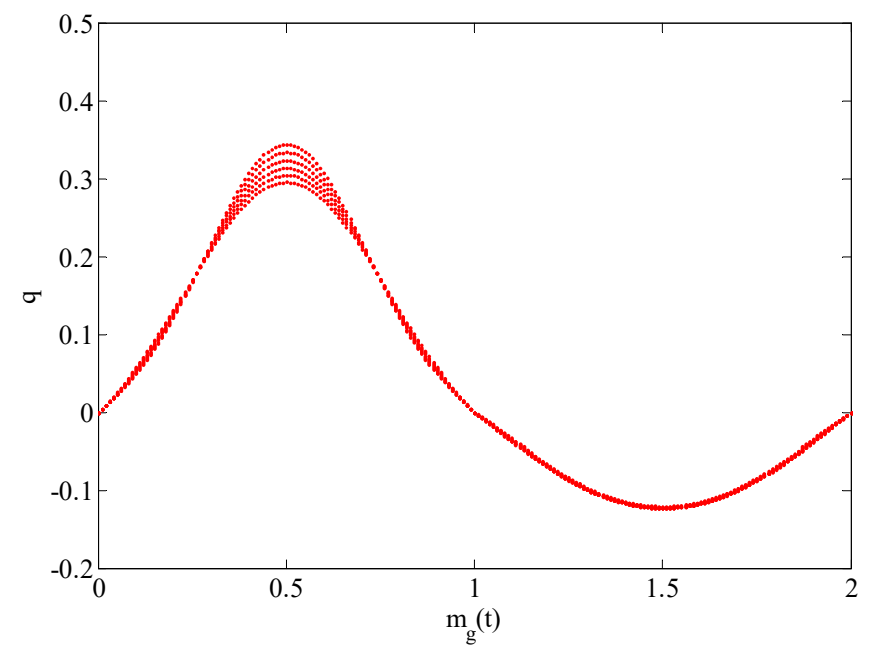

20 


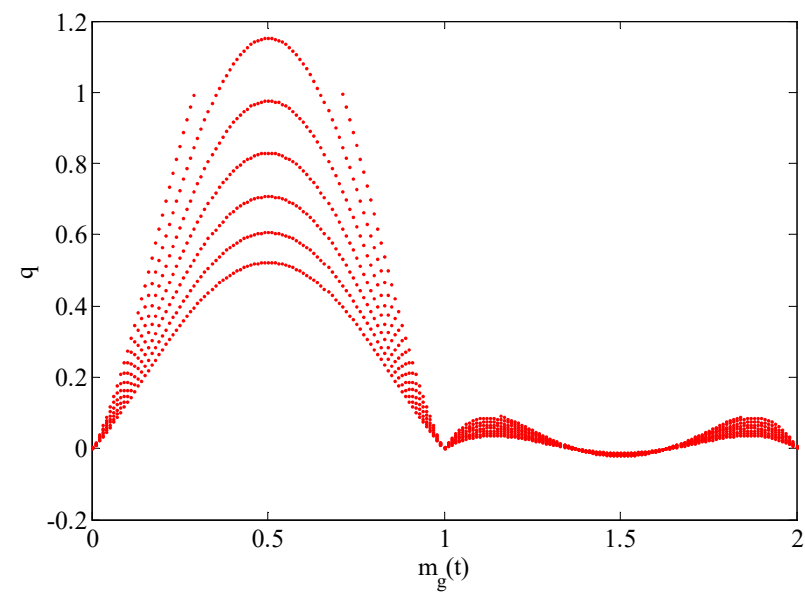




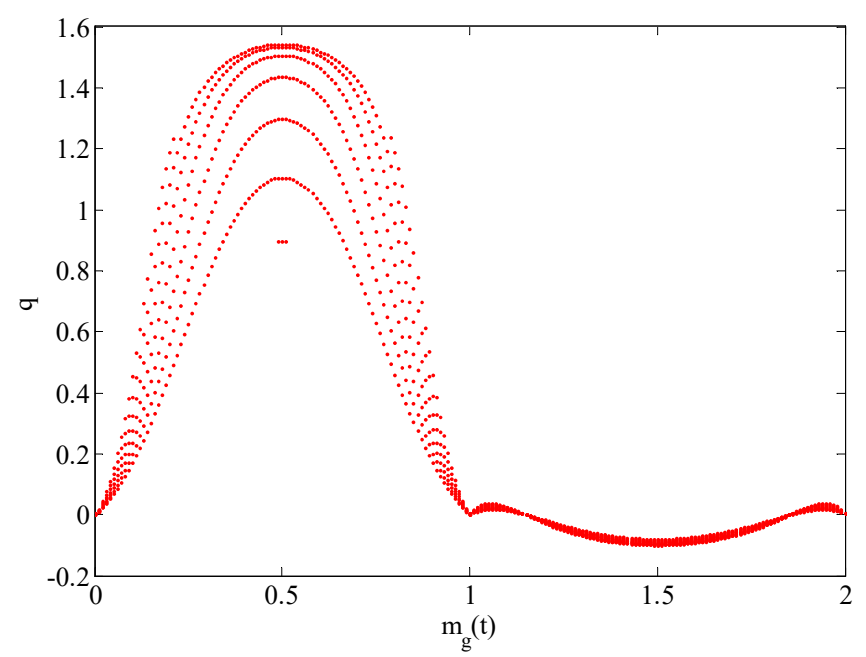

20 
(a)

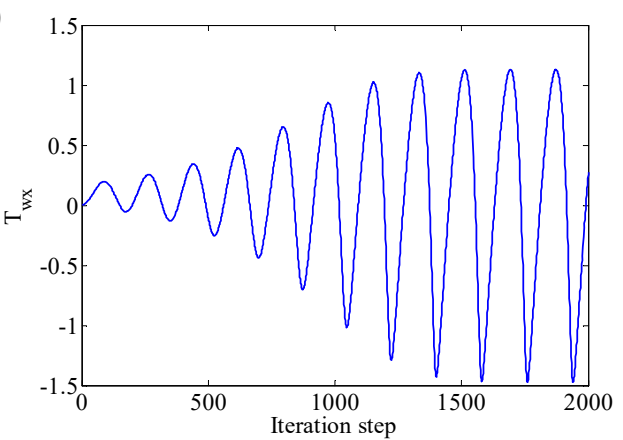

14

15

16 
(b)

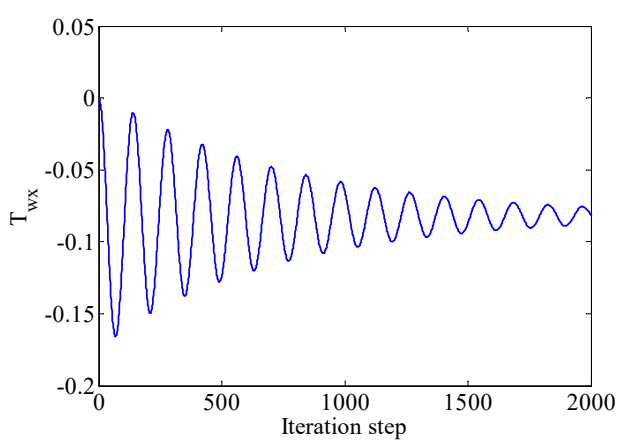

14

15

16

17 
(a)

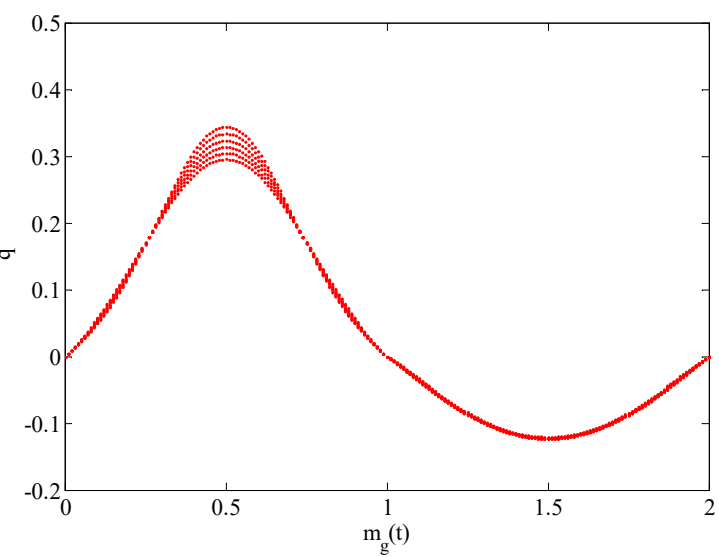

16 
(b)

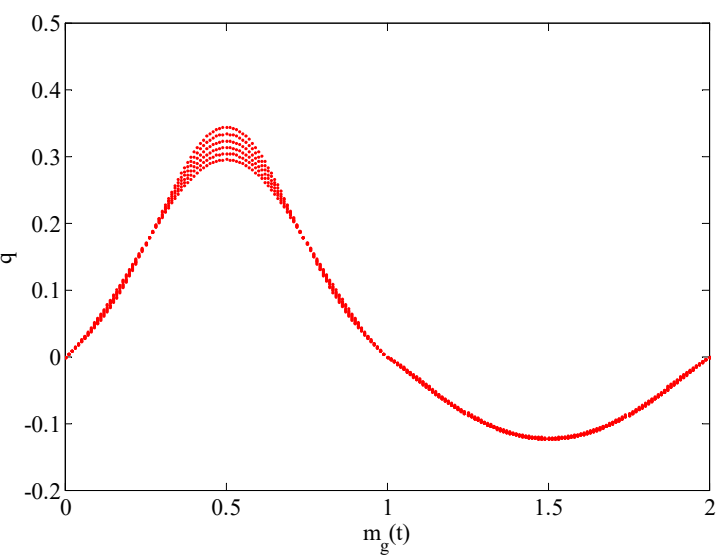

16 
(c)

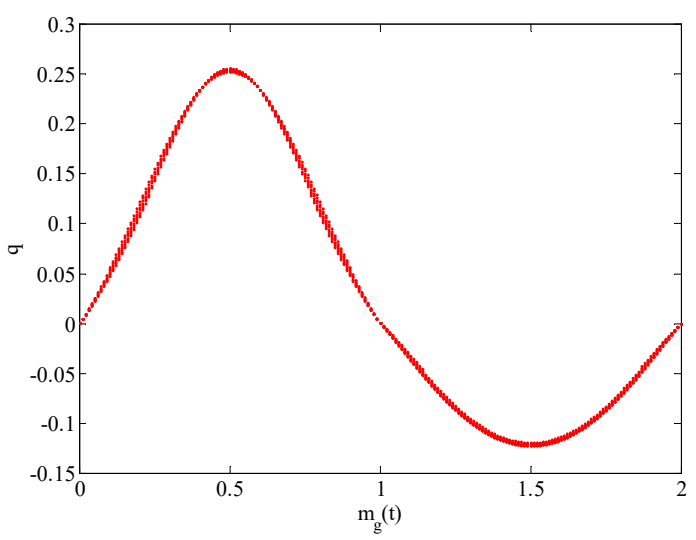

